This is a self-archiving document (manuscript version):

Electrospun sulfonated poly(ether ketone) nanofibers as proton conductive reinforcement for durable Nafion composite membranes

By: Klose, Carolin; Breitwieser, Matthias; Vierrath, Severin; Klingele, Matthias; Cho, Hyeongrae; Büchler, Andreas; Kerres, Jochen; Thiele, Simon

Published in: Journal of Power Sources

Volume 361, 1 September 2017, Pages 237-242 (Please be aware: Page numbering in this manuscript can be different to published version!)

Publisher: Elsevier | Year: 2017

DOI: $10.1016 /$ j.jpowsour.2017.06.080

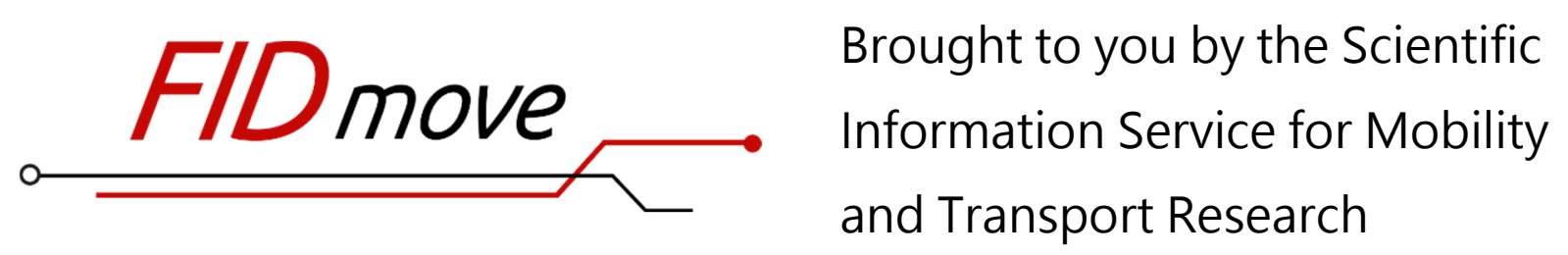

Fachinformationsdienst Mobilitäts- und Verkehrsforschung

Website: www.fid-move.de

Repository: publish.fid-move.de

Contact: publish@fid-move.de

(C) 2020. This manuscript version is made available under the CC-BY-

NC-ND 4.0 license.

http://creativecommons.org/licenses/by-nc-nd/4.0/ 


\title{
Electrospun sulfonated poly(ether ketone) nanofibers as proton conductive reinforcement for durable Nafion composite membranes
}

\author{
Carolin Klose ${ }^{a}$, Matthias Breitwieser ${ }^{\text {a, b }}$, Severin Vierrath ${ }^{\text {a, b }}$, Matthias Klingele ${ }^{\text {a }}$, \\ Hyeongrae Cho ${ }^{\mathrm{d}}$, Andreas Büchler ${ }^{\mathrm{e}}$, Jochen Kerres ${ }^{\mathrm{d}, \mathrm{f}}$, Simon Thiele ${ }^{\mathrm{a}, \mathrm{b}, \mathrm{c},{ }^{*}}$ \\ a Laboratory for MEMS Applications, IMTEK Department of Microsystems Engineering, University of Freiburg, Georges-Koehler-Allee 103 , 79110 Freiburg, \\ Germany \\ ${ }^{\mathrm{b}}$ Hahn-Schickard, Georges-Koehler-Allee 103, 79110 Freiburg, Germany

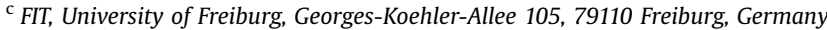 \\ ${ }^{\mathrm{d}}$ Institute of Chemical Process Engineering, University of Stuttgart, Boeblinger Str. 78, 70199 Stuttgart, Germany \\ e Fraunhofer Institute for Solar Energy Systems, Heidenhofstr.2, 79110 Freiburg, Germany \\ ${ }^{\mathrm{f}}$ Chemical Resource Beneficiation Faculty of Natural Science, North-West University, Potchefstroom, 2520, South Africa
}

A B S T R A C T

We show that the combination of direct membrane deposition with proton conductive nanofiber reinforcement yields highly durable and high power density fuel cells. Sulfonated poly(ether ketone) (SPEK) was directly electrospun onto gas diffusion electrodes and then filled with Nafion by inkjet-printing resulting in a $12 \mu \mathrm{m}$ thin membrane. The ionic membrane resistance $\left(30 \mathrm{~m} \Omega^{*} \mathrm{~cm}^{2}\right)$ was well below that of a directly deposited membrane reinforced with chemically inert (PVDF-HFP) nanofibers $\left(47 \mathrm{~m} \Omega^{*} \mathrm{~cm}^{2}\right.$ ) of comparable thickness. The power density of the fuel cell with SPEK reinforced membrane $\left(2.04 \mathrm{~W} / \mathrm{cm}^{2}\right)$ is $30 \%$ higher than that of the PVDF-HFP reinforced reference sample $\left(1.57 \mathrm{~W} / \mathrm{cm}^{2}\right)$. During humidity cycling and open circuit voltage (OCV) hold, the SPEK reinforced Nafion membrane showed no measurable degradation in terms of $\mathrm{H}_{2}$ crossover current density, thus fulfilling the target of $2 \mathrm{~mA} / \mathrm{cm}^{2}$ of the DOE after degradation. The chemical accelerated stress test $\left(100 \mathrm{~h} \mathrm{OCV}\right.$ hold at $90{ }^{\circ} \mathrm{C}$, $30 \% \mathrm{RH}, \mathrm{H}_{2} /$ air, $50 / 50 \mathrm{kPa}$ ) revealed a degradation rate of about $0.8 \mathrm{mV} / \mathrm{h}$ for the fuel cell with SPEK reinforced membrane, compared to $1.0 \mathrm{mV} / \mathrm{h}$ for the PVDF-HFP reinforced membrane.

G R A P H I C A L A B S T R A C T
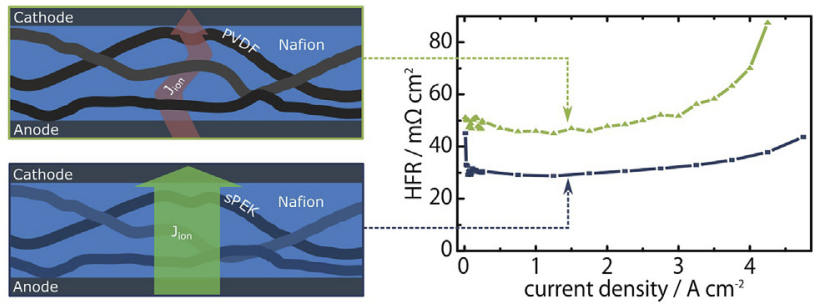

\section{Introduction}

To increase the lifetime of polymer electrolyte membrane fuel cells in order to make them relevant for automotive applications,

\footnotetext{
* Corresponding author. Laboratory for MEMS Applications, IMTEK Department of Microsystems Engineering, University of Freiburg, Georges-Koehler-Allee 103, 79110 Freiburg, Germany.

E-mail address: simon.thiele@imtek.de (S. Thiele).
}

Keywords:

PEMFC

Direct membrane deposition

Electrospinning

Composite membrane

Fiber reinforcement
H I G H L I G H T S

- A $12 \mu \mathrm{m}$ composite membrane is fabricated by direct membrane deposition.

- Proton conductive nanofiber reinforcement is used to reduce the membrane resistance.

- The power density increases by $30 \%$ compared to the reference.

- Chemical and mechanical long-term stability tests showed no measureable degradation. 
the US department of Energy (DOE) targets a fuel cell durability of $5000 \mathrm{~h}$ under automotive load cycling with a performance loss of less than $10 \%$ [1]. In order to achieve this target, fuel cell membranes need to be reinforced by composite structures, as pure perfluoro sulfonic acid (PFSA) membranes suffer from high chemical and mechanical degradation during fuel cell operation [2,3]. This typically leads to premature fuel cell end-of-life due to membrane failure. In order to address this problem multiple strategies for reinforcing PFSA membranes have been presented [4,5]. It has been found that fully connected, highly porous materialmatrices provide significant improvement of membrane life-time, especially when compared to simply blended composites [6-9]. In this regard, electrospinning provides a versatile and up-scalable tool for fabricating an interconnected network of nanofibers as reinforcing matrix. An overview of such material systems is given by Sood et al. [10]. Highly stable and inert materials, such as pol$\mathrm{y}$ (phenyl sulfone) (PPSU) [11,12], poly(vinylidene fluoride-co-hexafluoropropylene) (PVDF-HFP) [13] or polyvinyl alcohol (PVA) [11-15] have been demonstrated as electrospun fiber reinforcement with beneficial effects towards membrane stability.

However, as the above-mentioned reinforcement materials are not proton-conductive, the integration of such materials into PFSA membranes reduces its ionic conductivity, which results in a lower fuel cell power density. A few groups already addressed this issue. Li et al. modified the surface of PVDF-HFP nanofibers with polyelectrolytes and incorporated them into a Nafion membrane. They reported an increase of mechanical stability while maintaining a reasonable proton conductivity of $106 \mathrm{mS} / \mathrm{cm}[16,17]$. Mollá et al. functionalized the surface of PVA nanofibers with sulfonic acid groups before impregnating them with Nafion. This reduced the membrane resistance compared to a reinforcement with nonfunctionalized PVA fibers and maintained increased mechanical stability compared to a pure Nafion membrane [18-20]. Yao et al. integrated polystyrene fibers, which were sulfonated on the surface, into a Nafion membrane and thus created highly flexible freestanding membranes with proton conductivity of $180 \mathrm{mS} / \mathrm{cm}$, which is higher than recast Nafion membranes measured at same condition [21]. Shabani et al. integrated partially functionalized sulfonated poly(ether sulfone) nanofibers into a Nafion membrane and reported a proton conductivity comparable to that of pure Nafion membranes combined with an increase of proton to methanol selectivity in DMFCs [22]. Xu et al. fabricated composite membranes by infiltration of sulfonated poly(ether ether ketone) nanofibers with Nafion polymer and as well showed improved selectivity for methanol of up to $9.2^{*} 10^{4} \mathrm{sscm}^{-3}$ [23]. Jones et al. reported improved mechanical and chemical stability of a composite membrane when polybenzimidazole (PBI) nanofibers were integrated into a PFSA membrane due to an ionic cross-linking effect between PFSA and PBI nanofibers leading to a highly interconnected and proton conductive surface. In this work a decrease of membrane degradation during relative humidity $(\mathrm{RH})$ cycling at open circuit voltage (OCV) was reported [10]. However, apart from Jones et al., works that investigate performance and long-term stability in fuel cell operation of membranes with conductive reinforcement are still elusive.

In this work we fabricated Nafion membranes reinforced with proton-conductive sulfonated poly(ether ketone) (SPEK) nanofibers and thoroughly examine performance and long-term stability. The presented fuel cells are fabricated with direct membrane deposition (DMD) as first introduced by Klingele et al. [24]. In this process the conventional membrane foil is substituted by ionomer deposition directly onto the anode and cathode gas diffusion electrodes via inkjet-printing [24] or spray-coating [25]. DMD also enables simple fabrication of thin composite fuel cells, as shown by Breitwieser et al. by combining electrospinning and inkjet-printing 
[13]. We compare the DMD-SPEK fuel cell to a fuel cell with inert nanofiber membrane reinforcement (DMD-PVDF) and a commercially available state-of-the-art membrane (Gore-Select). This is the first time that the DMD method is combined with an ionically conducting nanofiber reinforcement.

The Gore-Select membrane was chosen as it presents one of the thinnest $(15 \mu \mathrm{m})$ commercially available PFSA membrane with inert reinforcement (expanded PTFE) and reflects the current automotive state-of-the-art [4,26-30].

In order to shorten the time for characterizing fuel cell membrane durability, various accelerated stress tests have been suggested by the department of energy [1]. The DOE suggests a steadystate open circuit voltage (OCV) hold to evaluate the chemical stability, and RH cycling to test the mechanical stability of the membrane. At OCV the reactant gases are not consumed, thus the partial pressure and, linked to that, gas crossovers are high compared to operation conditions where a certain current is drawn from the fuel cell [31]. Hence, a relatively large amount of crossover oxygen molecules is reduced at the Pt-catalyst of the anode side. This leads to hydrogen peroxide formation which further transforms into hydroxyl and hydroperoxyl radicals $(\cdot \mathrm{OH}$ and $\cdot \mathrm{OOH}$ ), ultimately causing chemical degradation of the membrane [32]. RH cycling causes mechanical stress within the fuel cell due to repetitive membrane swelling and contraction. This was found to be one reason for delamination of membrane and catalyst layer, as well as for pinhole formation [33].

\section{Methods}

\subsection{Fuel cell design and performance}

The fuel cells in this work were fabricated by the direct membrane deposition (DMD) method in which nanofibers were incorporated as reinforcement as previously presented by Breitwieser et al. [13,34]. According to this approach SPEK nanofibers were directly electrospun onto anode and cathode gas diffusion electrodes, and the pore space of the fibrous network was subsequently filled with Nafion ionomer by inkjet-printing. Gas diffusion electrode (GDE) substrates were purchased from Paxitech with a catalyst loading of $0.5 \mathrm{mg} / \mathrm{cm}^{2}$. The SPEK polymer for the nanofibers was synthesized according to Kerres et al. [35] and exhibits an ion exchange capacity of $1.8 \mathrm{meq} / \mathrm{g}$. In order to form a suitable solution for the electrospinning process, this polymer was dissolved in DMAc to yield a $26 \mathrm{wt} \%$ polymer solution. With this solution, nanofibers were deposited directly on gas diffusion electrodes at a voltage of $26 \mathrm{kV}$, a tip-to-collector distance of $6 \mathrm{~cm}$, a syringe pump rate of $3.15 \mu \mathrm{l} / \mathrm{min}$ and a rotating speed of the drum collector of $9 \mathrm{rpm}$. The fiber diameter was calculated with the plugin "local thickness" of the image processing program ImageJ based on scanning electron microscope images of the nanofiber network. The fuel cell was assembled as reported in the work of Breitwieser et al. [13]. A $50 \mu \mathrm{m}$ thick subgasket (Novofol, Germany) was used for sealing with an opening of $4 \mathrm{~cm}^{2}$.

Fuel cells with PVDF-HFP nanofiber reinforced Nafion membrane, fabricated as described by Breitwieser et al. [13] and named DMD-PVDF in the following, and a commercial Gore-Select membrane (15 $\mu \mathrm{m}$, ePTFE-reinforced) were used as references. The catalyst coated Gore-Select membrane was purchased from Paxitech, and contained the same loading of $0.5 \mathrm{mg} / \mathrm{cm}^{2}$ and the same gas diffusion layers as used for the DMD fuel cell experiments in this work. Thus, the MEAs were as comparable as possible. Fuel cells were tested with a commercial fuel cell testbench (850e, Scribner Associates Inc.). $180 \mu \mathrm{m}$ thick fiber reinforced PTFE gasketing material (Hightechflon, Germany) was used to achieve an adequate compression of the gas diffusion medium. 
Polarization curves were obtained by sweeping the cell current with an increment of $0.05 \mathrm{~A}$ and a hold time of 1 min per point below $1 \mathrm{~A}$ and an increment of $1 \mathrm{~A}$ and a hold time of 5 min per point above $1 \mathrm{~A}$. Operating conditions were $0.25 / 0.5 \mathrm{l} / \mathrm{min} \mathrm{H}_{2} / \mathrm{O}_{2}$, 99\% RH and atmospheric pressure. Before fuel cell testing a break-in procedure was performed consisting of two hours voltage hold and polarization curves cycling until the performance stabilized.

\subsection{Chemical and mechanical stability}

To study membrane stability under chemical degradation by free radicals, the fuel cell was held at open circuit voltage for $100 \mathrm{~h}$, at $90{ }^{\circ} \mathrm{C}, 30 \% \mathrm{RH}, 150 \mathrm{kPa}_{\mathrm{abs}}$ and at gas flows equivalent to stoichiometric flows of $10 / 10 \mathrm{H}_{2}$ /air at $0.2 \mathrm{~A} / \mathrm{cm}^{2}$ according to the respective DOE protocol [1]. To examine membrane degradation, the OCV was logged during the time of the accelerated stress test (AST).

To investigate membrane durability under solely mechanical stresses, an additional RH cycling AST was performed according to the DOE protocol [1]: to avoid chemically induced degradation mechanisms, the fuel cells were purged with nitrogen $(0.3 / 0.3 \mathrm{l} /$ min) without applying any electric potentials. The cell temperature was kept at $80^{\circ} \mathrm{C}$ and relative humidity was switched from $90^{\circ} \mathrm{C}$ dew point to completely dry operation conditions every two minutes for $100 \mathrm{~h}$ in total.

In order to monitor hydrogen gas cross-over due to pinhole formation and/or membrane thinning, linear sweep voltammetry (LSV) measurements were carried out before and after $100 \mathrm{~h}$ of AST at $80{ }^{\circ} \mathrm{C}$ cell temperature, $100 \% \mathrm{RH}, 0.25 / 0.05 \mathrm{l} / \mathrm{min} \mathrm{H}_{2} / \mathrm{N}_{2}$. The voltage was increased from $0 \mathrm{~V}$ to $0.6 \mathrm{~V}$ with an increment of $1 \mathrm{mV}$ and a hold time of $1 \mathrm{~s}$ at each point. The value of the hydrogen crossover current density was obtained by measuring the current density at $0.3 \mathrm{~V}$. Since below $0.3 \mathrm{~V}$ an influence by hydrogen which penetrated the membrane prior to measurement might be visible as a peak and at higher voltages the influence of electrical shorting might be more significant. However, in cases where cells show signs of electrical shorting the crossover current density might be overestimated due to an overlap of hydrogen crossover and electrical shorting. Since all cells in this work showed only soft signs of electrical shorting at a voltage of $0.3 \mathrm{~V}$, the hydrogen crossover current obtained at this point can be considered as reliable even without further correction. The electrical resistance of the cells was calculated via the slope of a linear fit in the range of $0.3 \mathrm{~V}-0.6 \mathrm{~V}$. Resistances over $1 \mathrm{k} \Omega^{*} \mathrm{~cm}^{2}$ were considered as infinite.

\section{Results \& discussion}

\subsection{Fuel cell design and performance}

Fig. 1a shows the electrospun SPEK-nanofibers with diameters of $250 \mathrm{~nm} \pm 150 \mathrm{~nm}$. The fiber network is directly electrospun on GDEs and impregnated with ionomer in the direct membrane deposition process. Fig. $1 \mathrm{~b}$ shows the assembled membrane coated GDEs with an overall thickness of $12 \mu \mathrm{m}$, a pure Nafion layer of $6 \mu \mathrm{m}$ in the middle and two outer layers with reinforcement of $3 \mu \mathrm{m}$ thickness.

Fig. 2a shows the polarization data of the DMD-SPEK fuel cell, and the DMD-PVDF and Gore-Select reference cells. The maximum power density of the DMD-SPEK cell is $30 \%$ higher $\left(2.04 \mathrm{~W} / \mathrm{cm}^{2}\right)$ than that of the PVDF-HFP reinforced fuel cell $\left(1.57 \mathrm{~W} / \mathrm{cm}^{2}\right)$ and $19 \%$ higher than the Gore-Select fuel cell $\left(1.71 \mathrm{~W} / \mathrm{cm}^{2}\right)$. The increase between DMD-SPEK and DMD-PVDF can be attributed to the lower membrane resistance given by the high frequency resistance (HFR) as shown in Fig. 2c. At a current density of $2 \mathrm{~A} / \mathrm{cm}^{2}$ the resistance is $30 \mathrm{~m} \Omega^{*} \mathrm{~cm}^{2}$ for the DMD-SPEK membrane and $45 \mathrm{~m} \Omega^{*} \mathrm{~cm}^{2}$ for the 
DMD-PVDF membrane. Although the membrane resistance of the Gore-Select membrane $\left(30 \mathrm{~m} \Omega^{*} \mathrm{~cm}^{2}\right.$ at $\left.2 \mathrm{~A} / \mathrm{cm}^{2}\right)$ is similar to that of the DMD-SPEK membrane, the DMD-SPEK fuel cell still shows better performance in the high current density region (above $3 \mathrm{~A} /$ $\mathrm{cm}^{2}$ ) than the fuel cell with Gore-Select membrane. This can be attributed to a lower mass transport resistance, which is typical for fuel cells fabricated with DMD as reported by Vierrath et al. [36]. They attribute the lower mass transport resistance to an increased water evacuation from cathode to anode due to an increased membrane surface. In summary, the combination of conductive reinforcement and DMD yields fuel cells with significantly improved membrane and overall performance.

\subsection{Chemical stability}

Fig. 3a shows the change of the OCV over $100 \mathrm{~h}$. The OCV decreases by $8 \%$ for the DMD-SPEK $(0.97 \mathrm{~V}-0.89 \mathrm{~V}, 0.80 \mathrm{mV} / \mathrm{h}), 11 \%$ for the DMD-PVDF sample $(0.92 \mathrm{~V}-0.82 \mathrm{~V}, 1.0 \mathrm{mV} / \mathrm{h})$ and $17 \%$ for the Gore-Select sample $(0.96 \mathrm{~V}-0.80 \mathrm{~V} ; 1.6 \mathrm{mV} / \mathrm{h})$. To get an estimation for long term behavior of the OCV, a linear fit of the last $60 \mathrm{~h}$ of the test (hours 40 to 100 ) has been performed. This yields almost similar degradation rates for the DMD-SPEK and DMD-PVDF [13] samples $(0.44 \mathrm{mV} / \mathrm{h}$ and $0.46 \mathrm{mV} / \mathrm{h}$ respectively). The degradation rate for the Gore-Select sample is almost unchanged, indicating an almost linear decay across the $100 \mathrm{~h}$ of testing $(1.41 \mathrm{mV} / \mathrm{h})$ [34].

The open circuit voltage depends besides kinetics mainly on crossover of hydrogen and internal electrical shorting [37].
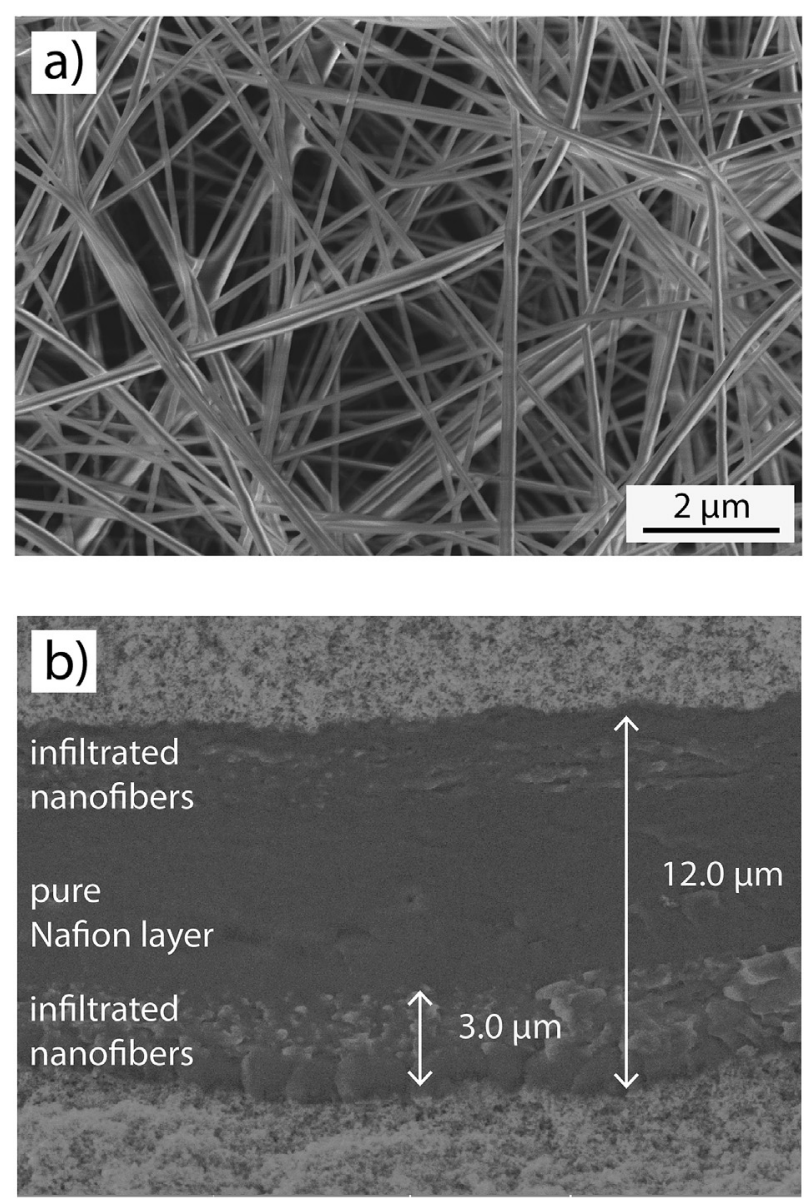

Fig. 1. a) Electrospun sulfonated poly(ether ketone) (SPEK) nanofibers. b) Cross section of the membrane with both electrodes. 
a)

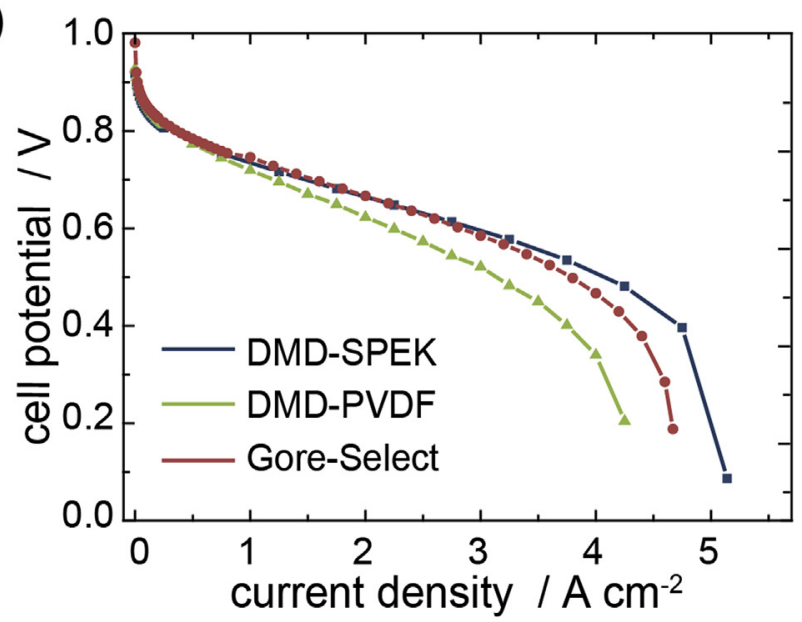

b)

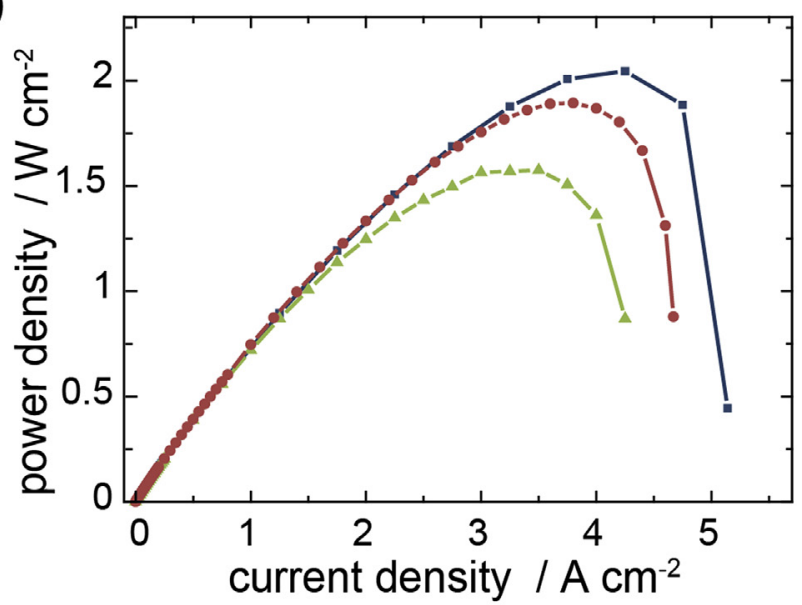

c)

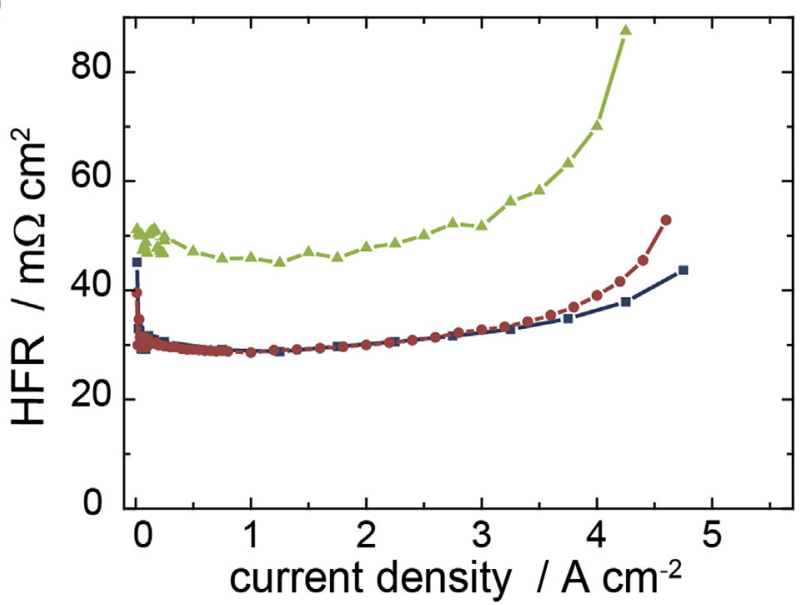

Fig. 2. In a) polarization data is shown from fuel cells with sulfonated poly(ether ketone) nanofiber reinforced Nafion membrane (blue squares), PVDF-HFP reinforced Nafion membrane (green triangles) and Gore-Select membrane (red dots). In b) the corresponding power density data and in c) the HFR is shown. The operating conditions were: $0.25 / 0.5 \mathrm{l} / \mathrm{min} \mathrm{H}_{2} / \mathrm{O}_{2}, 80{ }^{\circ} \mathrm{C}, 99 \% \mathrm{RH}$ and atmospheric pressure. (For interpretation of the references to colour in this figure legend, the reader is referred to the web version of this article.)

Additionally, the decay of the open circuit voltage during the $100 \mathrm{~h}$ of AST can be attributed to reversible degradation mechanisms like water flooding and platinum oxidation $[38,39]$. These reversible mechanisms explain the peak at $20 \mathrm{~h}$ of the OCV of the DMD-PVDF sample when water was drained from the backpressure unit. 
Hydrogen crossover current and electrical shorting can be extracted from linear sweep voltammetry measurements as shown in Fig. 3b. The linear sweep voltammetry measurements carried out at the beginning of the test (BOT) are displayed as solid lines. From this, the low OCV of the DMD-PVDF sample at the beginning of the test can be attributed to the low electrical resistance of this sample of $0.4 \mathrm{k} \Omega^{*} \mathrm{~cm}^{2}$ due to electrical shorting. The difference in OCV of the DMD-SPEK and the Gore-Select sample is minor and can be attributed to the higher hydrogen crossover of the Gore-Select membrane $\left(1.7 \mathrm{~mA} / \mathrm{cm}^{2}\right.$ vs. $\left.2.0 \mathrm{~mA} / \mathrm{cm}^{2}\right)$ since both samples exhibit high electrical resistances above $0.9 \mathrm{k} \Omega^{*} \mathrm{~cm}^{2}$.

For determining membrane degradation features caused by the accelerated stress test, LSV measurements have been also performed at the end of the test (EOT), visualized as dashed lines in Fig. 3b. The hydrogen crossover density of the DMD-SPEK membrane decreased during the duration of the test from $1.7 \mathrm{~mA} / \mathrm{cm}^{2}$ at the beginning of the test (BOT) to $0.8 \mathrm{~mA} / \mathrm{cm}^{2}$ at the end of the test (EOT) and a small electrical shorting $\left(0.9 \mathrm{k} \Omega^{*} \mathrm{~cm}^{2}\right)$ vanished. Thus, the accelerated stress test even led to reduced hydrogen crossover when using SPEK nanofibers as reinforcement. This behavior is in accordance with measurements from Breitwieser et al. who performed a $100 \mathrm{~h}$ OCV AST on a fuel cell with a Nafion membrane reinforced with cerium oxide decorated PVDF-HFP nanofibers [34].

a)
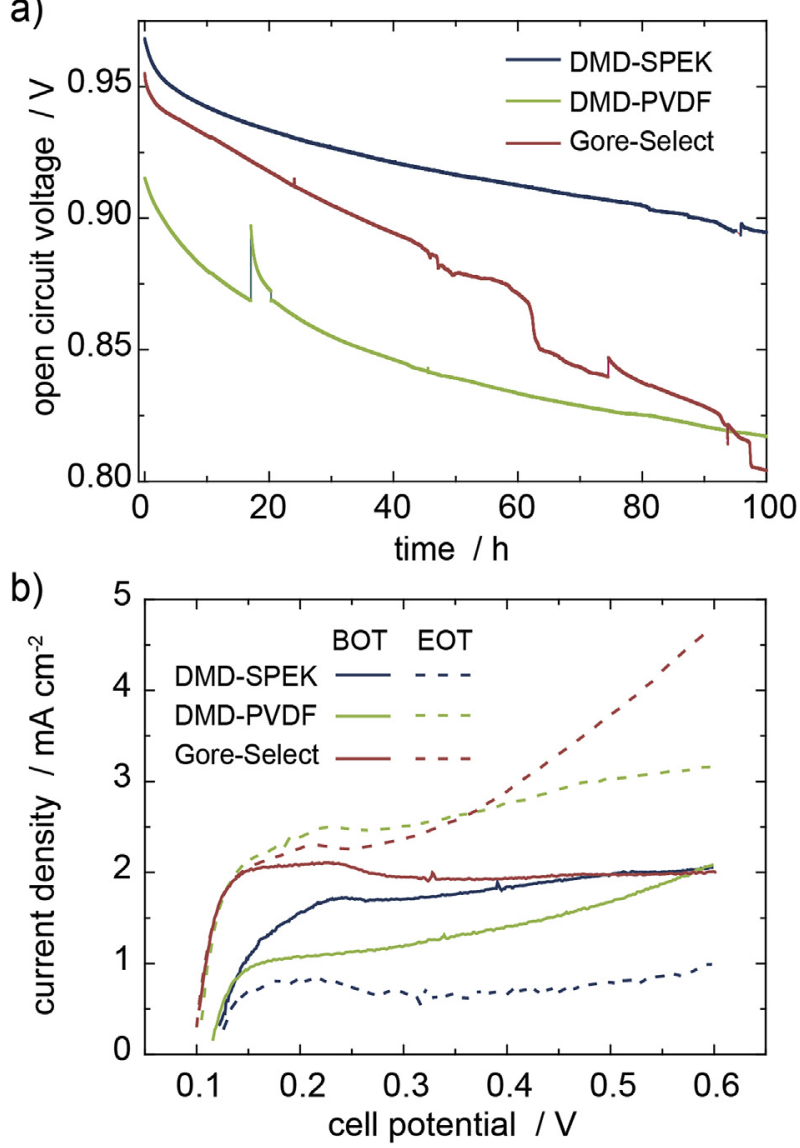

Fig. 3. In a) changes in the open circuit voltage of fuel cells with SPEK reinforced Nafion membrane (blue), PVDF-HFP reinforced Nafion membrane (green) and Goreselect membrane (red) over the time duration of the open circuit hold accelerated stress test (OCV hold AST) are shown. In b) linear sweep voltammetry data is shown as measured at the beginning (BOT - solid lines) and the end (EOT - dashed lines) of the OCV hold AST $\left(80^{\circ} \mathrm{C}, 100 \% \mathrm{RH}\right)$. Data for DMD-PVDF and Gore-Select are taken from Breitwieser et al. [13,34]. (For interpretation of the references to colour in this figure legend, the reader is referred to the web version of this article.) 
In contrast, the gas crossover of the DMD-PVDF membrane increased from $1.0 \mathrm{~mA} / \mathrm{cm}^{2}$ to $2.5 \mathrm{~mA} / \mathrm{cm}^{2}$ indicating membrane thinning, whereby the electrical resistance increased slightly from $0.3 \mathrm{k} \Omega^{*} \mathrm{~cm}^{2}$ to $0.5 \mathrm{k} \Omega^{*} \mathrm{~cm}^{2}$. The drastic decrease of OCV of the fuel cell with Gore-Select membrane can be attributed to the considerable decrease of electrical resistance to $0.2 \mathrm{k} \Omega^{*} \mathrm{~cm}^{2}$ of this sample. Thus, one could conclude that when using inert material as reinforcement, membrane degradation is promoted more intensively.

This is unintuitive, because at first sight one would think that inert materials are less susceptible to degradation. One possible explanation is a rearrangement of ionomer either due to the high temperature $\left(90^{\circ} \mathrm{C}\right)$ during the accelerated stress test which equals a hot pressing step. Since hot pressing is not performed prior to measurements, voids could be present in the material. Such voids could either occur due to insufficient infiltration or evaporation of remaining solvent. During the stress test at $90{ }^{\circ} \mathrm{C}$ voids could be filled by polymer during the OCV AST. This might be promoted when proton conductive nanofibers are incorporated into the Nafion membrane since SPEK and Nafion soften already at $90{ }^{\circ} \mathrm{C}$ whereas PVDF-HFP is stable up to higher temperatures.

Additionally, interaction between the sulfonic acid groups of SPEK and the Nafion membrane might cause a rearrangement of ion conducting domains along the fiber axis. As previous studies showed, such morphology changes during testing have the potential to change fuel cell behavior. Such morphology changes have been already reported when introducing sulfonated or basic materials into a PFSA matrix. When introducing S-PS nanofibers into the Nafion membrane, Yao et al. linked the high proton conductivity to a morphology change within the Nafion membrane caused by an orientation of the Nafion molecules by interacting with the $S$ PS fibers [21]. Also Li et al. attributed enhanced proton conductivity to the formation of proton conducting channels, suggesting a reorientation of hydrophobic and hydrophilic domains [16]. Effects of the nanofiber reinforcement on chemical and mechanical stability were not tested in those cases yet. Jones et al. for the first time reported chemical and mechanical stability improvement when introducing PBI nanofibers as reinforcement material into a PFSA matrix material. Here, the interaction is caused by ionic crosslinking between PFSA and basic PBI material [10]. Those findings suggest that interaction between Nafion and SPEK nanofibers could contribute to both chemical and mechanical stability of the membrane.

The drastic decrease of OCV for the Gore-Select membrane might be partly explained by the difference in fabrication technique. Reported degradation mechanisms such as cracks within the catalyst layer or delamination of the membrane $[33,40]$ might be reduced when using the DMD fabrication method. Vierrath et al. [36] showed that the ionic contact resistance between catalyst layer and polymer electrolyte membrane is lower when samples are fabricated by DMD compared to samples fabricated by the catalyst coated membrane method. Thus, the contact between catalyst layer and polymer electrolyte membrane is supposably better for DMD samples which could lead to a diminution of the previously mentioned degradation mechanisms.

\subsection{Mechanical stability}

A mechanical accelerated stress test consisting of $100 \mathrm{~h}$ of $\mathrm{RH}$ cycling showed a similar behavior of the LSV for all samples. Fig. 4 shows LSV measurements for all samples at the beginning (BOT) and the end of the test (EOT). At the beginning of the test the DMDSPEK membrane showed the highest hydrogen crossover density $\left(2.7 \mathrm{~mA} / \mathrm{cm}^{2}\right)$ and a soft electrical short $\left(0.9 \mathrm{k} \Omega^{*} \mathrm{~cm}^{2}\right)$. Both can be related to either cracks in the catalyst layer [41] or small surface in homogenities such as fibers of the gas diffusion layer protruding 


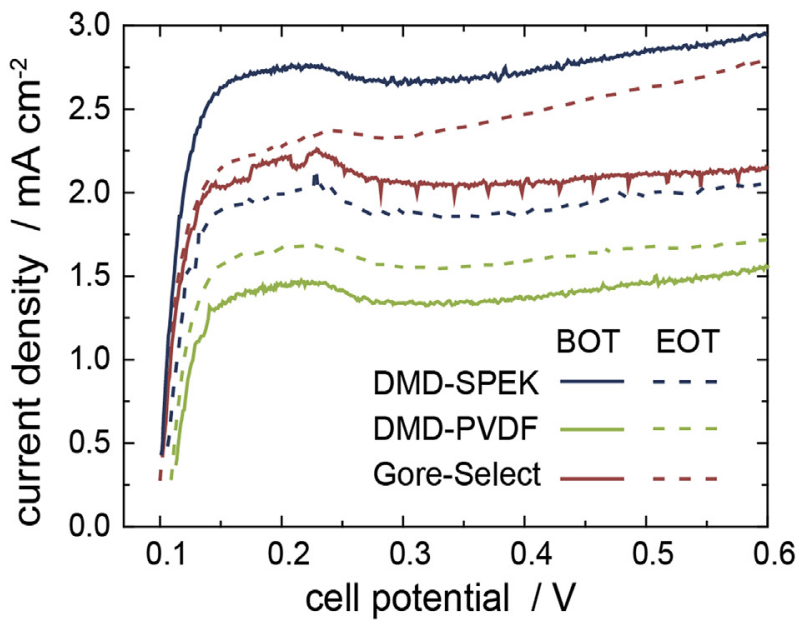

Fig. 4. Linear sweep voltammetry measurements at the beginning (BOT - solid lines) and the end (EOT - dashed lines) of the $100 \mathrm{~h}$ relative humidity cycling accelerated stress test, measured at $80^{\circ} \mathrm{C}$ and $100 \% \mathrm{RH}$.

the catalyst layer [42]. The Gore-Select membrane $\left(2.1 \mathrm{~mA} / \mathrm{cm}^{2}\right)$ showed a hydrogen crossover density in the range of the DOE target of $2 \mathrm{~mA} / \mathrm{cm}^{2}$. The hydrogen crossover density of the DMD-PVDF membrane $\left(1.4 \mathrm{~mA} / \mathrm{cm}^{2}\right)$ was well below the DOE target. No shorting was observed. At the end of the test, the gas crossover of the DMD-SPEK membrane decreased to a value of $1.9 \mathrm{~mA} / \mathrm{cm}^{2}$ and the small electrical short vanished. Thus, membrane quality of the SPEK reinforced Nafion membrane improved during the mechanical stability accelerated stress test as already observed for the chemical stability accelerated stress test. The hydrogen crossover density of the DMD-PVDF membrane $\left(1.6 \mathrm{~mA} / \mathrm{cm}^{2}\right)$ increased slightly and a minor internal shorting evolved, such that the shorting resistance still is above the target of the DEO of $1 \mathrm{k} \Omega^{*} \mathrm{~cm}^{2}$. The Gore-Select membrane showed a decrease of electrical resistance to $0.6 \mathrm{k} \Omega^{*} \mathrm{~cm}^{2}$. Thus, the DMD-PVDF membrane and the GoreSelect membrane showed signs of membrane degradation. When cycling the relative humidity, the inert reinforcement material and Nafion ionomer most likely delaminate due to the different swelling behavior of the two components. SPEK, as ion conductive material, reveals similar swelling behavior to that of Nafion, which probably reduces delamination issues. Another possible explanation might be an interaction of Nafion and the proton conductive SPEK fiber reinforcement as mentioned already earlier.

\section{Conclusion}

In this work the effect of integrating proton conductive SPEK nanofibers as reinforcement into a Nafion membrane by direct electrospinning and membrane deposition was shown. The proton conductivity of the fiber reinforcement led to a reduced membrane resistance and higher power density compared to a similarly fabricated composite membrane with inert reinforcement (PVDFHFP) material. The reinforcement effect of the SPEK nanofibers was confirmed by chemical and mechanical accelerated stress testing. Accelerated chemical degradation of the DMD-SPEK composite membrane by $100 \mathrm{~h}$ of open circuit voltage hold and accelerated mechanical degradation by $100 \mathrm{~h}$ of relative humidity cycling did not show any deterioration of the hydrogen cross over current and the electrical cell resistance, as proven by comparison of LSV measurements before and after the stress tests. The stress testing even led to an improvement of these parameters. We theorize that this might be due to void filling of Nafion dispersion promoted by the high temperature during OCV hold or similar swelling 
characteristics of Nafion and reinforcement material which reduces delamination when performing $\mathrm{RH}$ cycling. An additional impact might by caused by rearrangement of the sulfonic acid groups of the two proton conductive material components along the fiber axis. However, those theories need further evaluation.

Moreover, variance in electric resistance between the two electrodes over the membrane interface as well as in hydrogen cross-over, shows the influence of the substrate used for direct membrane deposition which will be looked at in more detail in the future. Future work will also include the evaluation of further combinations matrix ionomer/electrospun proton-conductive reinforcement.

\section{Acknowledgments}

The authors would like to acknowledge the Baden-Württemberg Stiftung for funding this work within the project "RePEM" in the Cleantech framework (Funktionelle Oberflächen und Materialien für die Energieversorgung der Zukunft, grant number: CT-1). The authors would like to thank Riko Moroni and Lukas Zielke for assistance with the graphical artwork.

\section{References}

[1] The Fuel Cell Technical Team, Fuel Cell Technical Team Roadmap, 2013. http://energy.gov/eere/vehicles/downloads/us-drive-fuel-cell-technical-teamroadmap. Accessed 19 August 2015.

[2] Y. Tang, A.M. Karlsson, M.H. Santare, M. Gilbert, S. Cleghorn, W.B. Johnson, Mater. Sci. Eng. A 425 (2006) 297-304.

[3] D. Liu, S. Case, J. Power Sources 162 (2006) 521-531.

[4] Jeffrey A. Kolde, Bamdad Bahar, Mahlon S. Wilson, Thomas A. Zawodzinski, Shimson Gottesfeld, Electrochem. Soc. Proc. 95-126 (1995) 193-201.

[5] R.M. Penner, C.R. Martin, J. Electrochem. Soc. (1985) 514-515.

[6] K.-Y. Cho, H.-Y. Jung, K.A. Sung, W.-K. Kim, S.-J. Sung, J.-K. Park, J.-H. Choi, Y.E. Sung, J. Power Sources 159 (2006) 524-528.

[7] H.J. Kim, H.J. Kim, Y.G. Shul, H.S. Han, J. Power Sources 135 (2004) 66-71.

[8] M.-K. Song, Y.-T. Kim, J.M. Fenton, H. Kunz, H.-W. Rhee, J. Power Sources 117 (2003) 14-21.

[9] Z.-g. Shao, X. Wang, I.-M. Hsing, J. Membr. Sci. 210 (2002) 147-153.

[10] R. Sood, S. Cavaliere, D.J. Jones, J. Rozière, Nano Energy 26 (2016) 729-745.

[11] J.B. Ballengee, P.N. Pintauro, J. Membr. Sci. 442 (2013) 187-195.

[12] J.B. Ballengee, P.N. Pintauro, Macromolecules 44 (2011) 7307-7314.

[13] M. Breitwieser, C. Klose, M. Klingele, A. Hartmann, J. Erben, H. Cho, J. Kerres, R. Zengerle, S. Thiele, J. Power Sources 337 (2017) 137-144. 
[14] S.W. Choi, Y.-Z. Fu, Y.R. Ahn, S.M. Jo, A. Manthiram, J. Power Sources 180 (2008) 167-171.

[15] H.-L. Lin, S.-H. Wang, C.-K. Chiu, T.L. Yu, L.-C. Chen, C.-C. Huang, T.-H. Cheng, J.M. Lin, J. Membr. Sci. 365 (2010) 114-122.

[16] H.-Y. Li, Y.-L. Liu, J. Mater. Chem. A 2 (2014) 3783.

[17] H.-Y. Li, Y.-Y. Lee, J.-Y. Lai, Y.-L. Liu, J. Membr. Sci. 466 (2014) 238-245.

[18] S. Mollá, V. Compañ, J. Membr. Sci. 372 (2011) 191-200.

[19] S. Mollá, V. Compañ, E. Gimenez, A. Blazquez, I. Urdanpilleta, Int. J. Hydrogen Energy 36 (2011) 9886-9895.

[20] S. Mollá, V. Compañ, J. Power Sources 196 (2011) 2699-2708.

[21] Y. Yao, L. Ji, Z. Lin, Y. Li, M. Alcoutlabi, H. Hamouda, X. Zhang, Appl. Mater. Interfaces 3 (2011) 3732-3737.

[22] I. Shabani, M.M. Hasani-Sadrabadi, V. Haddadi-Asl, M. Soleimani, J. Membr Sci. 368 (2011) 233-240.

[23] X. Xu, L. Li, H. Wang, X. Li, X. Zhuang, RSC Adv. 5 (2015) 4934-4940.

[24] M. Klingele, M. Breitwieser, R. Zengerle, S. Thiele, J. Mater. Chem. A 3 (2015) $11239-11245$.

[25] M. Klingele, B. Britton, M. Breitwieser, S. Vierrath, R. Zengerle, S. Holdcroft, S. Thiele, Electrochem. Commun. 70 (2016) 65-68.

[26] Shinji Kinoshita and Hiroshi Shimoda, Performances of Highly Durable PFSA Polymer based MEAs at High Temperature, Low RH and Dry-Wet Conditions, 21 th-24th 2008, Progress in MEA, La Grande Motte, France.

[27] W. Liu, K. Ruth, G. Rusch, J. New Mater. Electrochem. Syst. 4 (2001) 227-232.

[28] W.L. Gore, Associates Inc, Membr. Technol. 2016 (2016) 4.

[29] X. Zhang, Y. Rui, Z. Tong, X. Sichuan, S. Yong, N. Huaisheng, Int. J. Hydrogen Energy 39 (2014) 9420-9429.

[30] G. Ding, M.H. Santare, A.M. Karlsson, A. Kusoglu, J. Power Sources 316 (2016) $114-123$.

[31] M. Inaba, T. Kinumoto, M. Kiriake, R. Umebayashi, A. Tasaka, Z. Ogumi, Electrochim. Acta 51 (2006) 5746-5753.

[32] A.B. LaConti, M. Hamdan, R.C. McDonald (Eds.), Mechanisms of Membrane Degradation, Wiley Online Library, 2003.

[33] X. Huang, R. Solasi, Y. Zou, M. Feshler, K. Reifsnider, D. Condit, S. Burlatsky, T. Madden, J. Polym. Sci. B Polym. Phys. 44 (2006) 2346-2357.

[34] M. Breitwieser, C. Klose, A. Hartmann, A. Büchler, M. Klingele, S. Vierrath, R. Zengerle, S. Thiele, Adv. Energy Mater 7 (2017) 1602100.

[35] J.A. Kerres, Fuel Cells 5 (2005) 230-247.

[36] S. Vierrath, M. Breitwieser, M. Klingele, B. Britton, S. Holdcroft, R. Zengerle, S. Thiele, J. Power Sources 326 (2016) 170-175.

[37] J. Larminie, A. Dicks, Fuel Cell Systems Explained, first ed., Wiley Verlag, Chichester, 2000.

[38] S. Kundu, M. Fowler, L.C. Simon, R. Abouatallah, J. Power Sources 182 (2008) $254-258$.

[39] C. Eickes, P. Piela, J. Davey, P. Zelenay, J. Electrochem. Soc. 153 (2005) A171-A178.

[40] S. Kundu, M.W. Fowler, L.C. Simon, S. Grot, J. Power Sources 157 (2006) 650-656.

[41] T. Bayer, H.C. Pham, K. Sasaki, S.M. Lyth, J. Power Sources 327 (2016) 319-326.

[42] M. Breitwieser, T. Bayer, A. Büchler, R. Zengerle, S.M. Lyth, S. Thiele, J. Power Sources 351 (2017) 145-150. 